\title{
Phylogenetic and multivariate analyses to determine the effect of agricultural land-use intensification and soil physico-chemical properties on N-cycling microbial communities in drained Mediterranean peaty soils
}

Valentina Ciccolini 1 ,

Phone $+39-050-883181$

Fax +39-050-883526

Emailv.ciccolini@sssup.it

Enrico Bonari 1

Laura Ercoli 1

Elisa Pellegrino

${ }^{1}$ Institute of Life Sciences, Scuola Superiore Sant'Anna, P.za Martiri della Libertà 33, 56127 Pisa, Italy

\section{Abstract}

This study aims to provide first insights on the impact of land-use intensification and soil properties in shaping the composition of $\mathrm{N}$ cycling microbial communities in Mediterranean peaty soils drained for agricultural purposes. An intensively cultivated peaty soil represented by an intensive maize cropping system was compared with an extensive grassland and an agricultural soil left abandoned for 15 years. Clonelibrary sequencing based on partial amo $A$ and nirK functional genes was used to characterize the composition of ammonia-oxidizer microorganisms and nirK-type bacterial denitrifiers, respectively. The relative roles of land-use intensification and soil physico-chemical properties in community composition shaping were quantified by multivariate analyses. Phylogenetic and multivariate analyses showed 
that (i) the majority of sequences of ammonia-oxidizing archaea (AOA) and ammonia-oxidizing bacteria (AOB) grouped within the Nitrosotalea and Nitrosospira clusters, respectively; (ii) uncultured denitrifying bacteria were unique to our soil; (iii) land-use intensification shaped the composition of N-cycling communities; (iv) ammonia-oxidizing communities were driven by clay (AOA), bulk density (AOB), and exchangeable calcium (both AOA and AOB); and (v) nirK-type denitrifier bacteria were shaped by silt, ammonium, and exchangeable potassium. Based on the variation partitioning, soil properties were the primary determinants of the AOA and nirK-type denitrifier community composition, while land-use intensification was the major factor shaping the community composition of AOB. These findings improve the knowledge on such vulnerable agrosystems aiming to optimize the management of soil microbes in order to enhance the sustainability of $\mathrm{N}$ fertilization.

\section{Keywords}

Land-use change

Ammonia-oxidizing archaea (AOA)

Ammonia-oxidizing bacteria (AOB)

nirK

Nitrogen cycle

Microbial diversity

\section{Electronic supplementary material}

The online version of this article (doi: 10.1007/s00374-016-1121-9) contains supplementary material, which is available to authorized users.

\section{Introduction}

Soil microorganisms are key players in agrosystem functioning since they drive primary and secondary production and nutrient cycles (Nannipieri et al. 2002; Bardgett et al. 2005). In particular, nitrifier and denitrifier microorganisms play key roles in the nitrogen $(\mathrm{N})$ cycle through the nitrification and denitrification processes. $\mathrm{N}$ is the most important nutrient for crop growth and the major element supplied by fertilization (Smil 1997). It has been estimated that in Europe $\mathrm{N}$ input exceeds $\mathrm{N}$ output by crop uptake by $10-240 \mathrm{~kg} \mathrm{~N} \mathrm{ha}^{-1}$ per year (Velthof et al. 2011). It has 
been calculated that $\mathrm{N}$-fertilization efficiency of crop production does not exceed $30 \%$, which implies high economic and environmental costs (Tilman et al. 2002). Excess $\mathrm{N}$ input into the soil changes rates of $\mathrm{N}$ transformation, which increases the pathways for $\mathrm{N}$ loss: about $50-60 \%$ of the $\mathrm{N}$ surplus is lost as molecular $\mathrm{N}\left(\mathrm{N}_{2}\right)$ emissions, followed by ammonia $\left(\mathrm{NH}_{3}\right)$ emissions, nitrate $\left(\mathrm{NO}_{3}{ }^{-}\right)$leaching, and run-off and nitrous oxide $\left(\mathrm{N}_{2} \mathrm{O}\right)$ and mono-nitrogen oxide $\left(\mathrm{NO}_{\mathrm{x}}\right)$ emissions (De Vries et al. 2011; Velthof et al. 2011). Moreover, $\mathrm{N}$ fertilizer surplus increases the decomposition rate of crop residues and soil organic matter (SOM), with a net decline in soil carbon (C) content and soil fertility (Khan et al. 2007; Philippot et al. 2007).

AQ1

Nitrification is a two-step process that includes the oxidation of $\mathrm{NH}_{3}$ into nitrite $\left(\mathrm{NO}_{2}{ }^{-}\right)$by ammonia-oxidizer microorganisms and its subsequent oxidation into $\mathrm{NO}_{3}{ }^{-}$by nitrite-oxidizer bacteria (De Boer and Kowalchuk 2001; Treusch et al. 2005; Stahl and de la Torre 2012). Denitrification is the anaerobic process performed by denitrifier microorganisms in which $\mathrm{NO}_{2}{ }^{-}$and $\mathrm{NO}_{3}{ }^{-}$(both $\mathrm{N}$ oxides) are used as electron acceptors and reduced to $\mathrm{N}_{2}$ via nitric oxide (NO) and $\mathrm{N}_{2} \mathrm{O}$ (Zumft 1997).

Ammonia oxidation, the first and rate-limiting step of nitrification, is catalyzed by aerobic chemolithoautotrophic ammonia-oxidizing bacteria (AOB), which are mainly composed of Nitrosomonas and Nitrosospira genera from the $\beta$-subclasses of Proteobacteria (Purkhold et al. 2000) and by ammonia-oxidizing archaea (AOA) from the new phylum Thaumarchaeota (Pester et al. 2011; Stahl and de la Torre 2012). Both these groups employ the functional amoA gene, encoding the $\alpha$-subunit of ammonia monooxygenase, which catalyzes the oxidation of $\mathrm{NH}_{3}$ into hydroxylamine $\left(\mathrm{NH}_{2} \mathrm{OH}\right)$ (Kowalchuk and Stephen 2001 ; Pester et al. 2011). Regarding denitrification, a wide range of phylogenetically distant microorganisms from $\alpha$ - and $\beta$-subclasses of Proteobacteria, archaea, and fungi have been reported to use $\mathrm{N}$ oxides as final electron acceptors (Zumft 1997; Hayatsu et al. 2008). These groups employ several functional genes encoding key enzymes, such as reductases for $\mathrm{NO}_{3}{ }^{-}$(periplasmatic and membrane-bound: napA and $\operatorname{nar} G$ gene), $\mathrm{NO}_{2}{ }^{-}$(cytochrome cd1- and copper-containing: nirS and nirK gene), NO (cytochrome and quinola: cnor $B$ and qnor $B$ gene), and $\mathrm{N}_{2} \mathrm{O}$ (nos $Z$ gene) (Philippot et al. 2007). 
In agricultural soils, $\mathrm{N}$-cycling communities and their functionality may be greatly affected by land-use intensification (Bardgett et al. 2005).

Specifically, intensive agricultural practices, such as tillage, fertilization, weed management, and mowing, can have great impact on the composition of nitrifier and denitrifier microorganisms. Tillage has been reported to decrease the abundance of AOA and AOB and the diversity of AOB (Bruns et al. 1999; Li et al. 2015) and to modify the composition of the nirK-type bacterial denitrifier community (Smith et al. 2010; Pastorelli et al. 2011, 2013 ). Similarly, N fertilization and weed management significantly decreases $\mathrm{AOA}, \mathrm{AOB}$, and nirK-type bacterial denitrifier abundance and affects the composition of only AOA communities (He et al. 2007; Hallin et al. 2009; Chen et al. 2011; Kastl et al. 2015; Wang et al. 2015). With regard to mowing, although no effects were observed on nirK-type bacterial denitrifiers, strong decreases were reported in AOA and AOB abundances, with few effects on community composition (Zhang et al. 2013; Chen et al. 2014; Xie et al. 2014).

With regard to soil properties, soil moisture, and temperature (Avrahami and Bohannan, 2007), pH (Kowalchuk and Stephen, 2001; Nicol et al. 2008; Jiang et al. 2015), clay, organic C and soil structure (Pereira e Silva et al. 2012; Wessén et al. 2011), and ammonium $\left(\mathrm{NH}_{4}{ }^{+}\right)$and $\mathrm{NO}_{3}{ }^{-}$ concentrations (Philippot et al. 2009; Tian et al. 2014) were reported to considerably affect AOA and AOB abundances and composition. Similarly, nirK-type bacterial denitrifier communities are shaped by several physicochemical properties, such as soil aeration, temperature, $\mathrm{pH}$, copper, clay, organic C, and $\mathrm{NO}_{3}{ }^{-}$availability (Philippot et al. 2007; Kastl et al. 2015).

Although the distribution of nitrifiers and denitrifiers in agricultural soils has been widely investigated, only little is known about their distribution in peaty soils (Andert et al. 2011; Herrmann et al. 2012). Peaty soils cover almost $3 \%$ of the global surface area and represent a major store of soil $\mathrm{C}$ (approximately $50 \%$ of the soil organic $\mathrm{C}$ in the world), a sink for carbon dioxide $\left(\mathrm{CO}_{2}\right)$, and a source of atmospheric methane (Strack 2008). About $14 \%$ of European peatlands are currently used for agriculture after drainage. Drainage increases $\mathrm{N}$ and $\mathrm{P}$ availability to crops due to peat mineralization during the first years after drainage but also increases mineralization rates, leading to soil-surface subsidence, nutrient leaching, and a high increase in $\mathrm{CO}_{2}$ and $\mathrm{N}_{2} \mathrm{O}$ emissions into the atmosphere (Oleszczuk et al. 2008). Regarding the $\mathrm{N}$ cycle, since nitrification and 
denitrification are intensified in drained peatlands, studying changes in Ncycling communities due to land-use intensification is crucial for sustainable management of these agrosystems.

Therefore, in this study, we assessed, for the first time in Mediterranean peaty soils drained for agricultural purposes, effects of land-use intensification on ammonia-oxidizer microorganisms and nirK-type bacterial denitrifiers. To this end, an intensively cultivated peaty soil represented by a continuous maize (Zea mays L.) cropping system was compared with an extensive grassland and an agricultural soil left abandoned for 15 years. Clone-library sequencing based on amo A and nirK genes was used to characterize the composition of N-cycling communities. We hypothesized that land-use intensification in peaty soils would negatively affect diversity and functional composition of the N-cycling communities and would be the major driver in shaping these communities with respect to the main soil physico-chemical soil properties that were already shown to significantly impact the fungal communities in the same site (Ciccolini et al. 2015).

\section{Materials and methods}

\section{Field site and experimental setup}

The experimental site is located in the southern portion of the Massaciuccoli Lake basin $\left(43^{\circ} 49^{\prime} \mathrm{N}, 10^{\circ} 19^{\prime} \mathrm{E}\right)$ (Pisa, Italy). The organic horizon of the field site is about $3 \mathrm{~m}$ (range 2-4 m) thick, with a mean SOM content of $29.2 \%$ (range 20.1-55.4\%, Walkley-Black method), a clay content of $25 \%$, and a bulk density of $0.5 \mathrm{~g} \mathrm{~cm}^{-3}$ in the topsoil layer (0-30 cm deep). The soil is classified as Histosol according to the USDA system (Soil Survey Staff 1975) and defined as peaty soil (IPCC, 2006). Details of the soil texture are given in Table S1 (Online Resource 1). The climate is Mediterranean, according to Köppen classification, with dry and hot summers and rainfall mainly concentrated in autumn and spring (mean annual rainfall, ca. $945 \mathrm{~mm}$ year ${ }^{-1}$ ) and mean monthly air temperature ranging from $7{ }^{\circ} \mathrm{C}$ in February to $30{ }^{\circ} \mathrm{C}$ in August (mean $=14.8^{\circ} \mathrm{C}_{\text {year }}{ }^{-1}$ ).

The long-term (15-year) experiment was a completely randomized design with land-use intensification as the treatment and three replicates $(n=3$; field replicates of $0.7 \mathrm{ha}$ ). The site was cultivated with maize until 15 years ago when the experiment was established by the abandonment of 
agricultural practices in an area of about 15 ha. In such an area, natural succession vegetation was left to develop with or without mowing. The surrounding area is still cultivated with maize. In detail, the land-use types were set up as follows: (i) an intensive cropping system (high intensity, HI) based on maize (Zea mays L.) that was carried out for the last 15 years. In HI, field replicates were plowed $(30-35 \mathrm{~cm})$, harrowed, and sown with maize at the beginning of June. Crops were harvested in late September. Mechanical and chemical post-emergence weed control was also applied: 3,6-dichloro-2-methoxybenzoic acid (dicamba) (at a rate of $1 \mathrm{~L} / \mathrm{ha}$ ) and nicosulfuron (at a rate of $1.5 \mathrm{~L} / \mathrm{ha}$ ). No pest management was applied. Details of the sowing and fertilization are found in Pellegrino et al. (2014). (ii) An extensive grassland (low intensity, LI): LI is an agricultural soil where agricultural practices (i.e., crop sowing, tillage, fertilization, and pest management) were stopped 15 years ago with the exception of the vegetation mowing and removal twice a year. In LI, indigenous vegetation was mainly composed by Portulaca oleracea L., Capsella bursa-pastoris (L.) Med., Juncus bufonius L., Polygonum persicaria L., Sorghum halepense (L.) Pers., Cynodon dactylon (L.) Pers., Datura stramonium L., Rumex crispus L., Echinochloa crus-galli (L.) Beauv., Calystegia sp., and Amaranthus retroflexus L. (iii) An agricultural soil left abandoned (zero intensity, ZI): ZI is an agricultural soil abandoned 15 years ago, when crop sowing, fertilization, tillage, and other agricultural practices were stopped and the indigenous grasses were left to develop as natural colonizers. The most abundant plant species was Phragmites australis (Cav.) Trin. ex Steud. A detailed list of the plant species composition is given by Pellegrino et al. (2014). Distances between land-use sites were ca. $600 \mathrm{~m}$. Further details on soil physico-chemical properties and analytical methods are provided in Online Resource 1 (data on soil texture and physicochemical properties in Tables S1 and S2, respectively).

\section{Sampling and analyses}

In late July 2011, one soil sample resulting from pooling seven bulk soil cores $(\varnothing=5 \mathrm{~cm})$ was collected $(0-30 \mathrm{~cm}$ in depth) from each of the three field replicates per treatment (a total of nine bulk soil samples) to cover chemical and soil microbial spatial variability. Soil sampling was performed only once, in July, since it should not occur close to soilmanagement practices (Alef and Nannipieri 1995; Pellegrino et al. 2011) and since soil microbial communities consistently maintain the same 
pattern of variability in differently managed ecosystems, albeit with seasonal changes due to abiotic conditions (i.e., soil moisture and temperature) (Wolsing and Priemé 2004; Stres et al. 2008; Wertz et al. 2009; Chen et al. 2014; Delmont et al. 2014). Each of the nine bulk soil samples were stored in an ice box, transported to the laboratory, and stored in ice until the analysis. Soil samples were sieved at $2 \mathrm{~mm}$. Soil $\mathrm{N}$ analyses were conducted within a maximum of 2 days. Then, a subsample of the remaining soil was oven dried at $60^{\circ} \mathrm{C}$ for chemical property determinations and a subsample stored at $-20{ }^{\circ} \mathrm{C}$ for extraction of soil genomic DNA and construction of clone libraries.

Soil DNA was extracted from a 0.5 -g subsample of soil using the PowerSoil ${ }^{\circledR}$ MO BIO kit (MO BIO Laboratories Inc., Carlsbad, CA, USA). DNA quality was checked by a ND-1000 spectrophotometer (NanoDrop Technology, Wilmington, DE, USA). The primer pairs Arch-amoAF and Arch-amoAR (Francis et al. 2005) and amoA 1F and amoA 2R (Rotthauwe et al. 1997) were used to perform PCR amplification of AOA and AOB partial amoA genes, respectively. A part of the functional nirK gene, encoding copper-containing nitrite reductase, was PCR-amplified using the primer pair nirK 1F-nirK 5R (Throbäck et al. 2004). PCRs were performed using the thermal profiles shown in Table S3 (Online Resource 1). PCR amplicons were generated from $10 \mathrm{ng} \mu \mathrm{L}^{-1}$ genomic DNA in volumes of $20 \mu \mathrm{L}$ with $0.5 \mathrm{U}$ of GoTaq ${ }^{\circledR}$ Hot Start Polymerase (Promega Corporation, Madison, WI, USA), $10 \mathrm{nM}$ of each primer, $0.2 \mathrm{mM}$ of each $\mathrm{dNTP}, 1.25 \mu \mathrm{M}$ of $\mathrm{MgCl}_{2}$, and $1 \times$ reaction buffer, using the $\mathrm{S} 1000$ Thermal

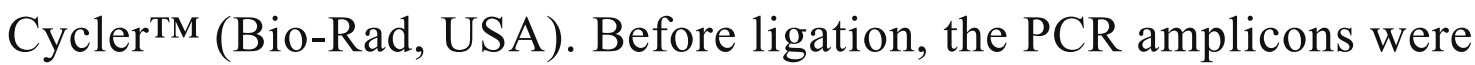
checked by a spectrophotometer (NanoDrop Technology, Wilmington, DE, USA) for quantity and quality then were ligated into the pGem ${ }^{\circledR}-T$ Easy vector (Promega Corporation, Madison, WI, USA) and used to transform XL10-Gold ${ }^{\circledR}$ ultracompetent Escherichia coli cells (Stratagene ${ }^{\circledR}$, La Jolla, CA, USA).

Each library (nine libraries for each microbial group) was screened for colonies containing inserts of the correct size. At least 25 positive clones per library were sequenced using Arch-amoAF, amoA 1F, and nirK $1 \mathrm{~F}$ primers for $\mathrm{AOA}, \mathrm{AOB}$, and nirK-type bacterial denitrifiers, respectively, in an ABI Prism ${ }^{\circledR}$ 3730XL automated sequencer (Applied Biosystems, Foster City, CA, USA) at the High-Throughput Genomics Unit (Seattle, WA, USA). 


\section{Phylogenetic analysis}

Reference datasets of public sequences for each microbial group were created using only sequences of pure cultured organisms (these alignments are open-access at

https://sites.google.com/site/restomedpeatland/microbiology ). The reference datasets were used for further alignment of the newly generated sequences, after checking the quality of their electropherograms with Vector NTI. Affiliations of the newly generated AOA, AOB, and nirK-type denitrifier sequences were verified using the BLAST tool in GenBank. For each microbial group, the alignments for constructing the phylogenetic trees also included environmental GenBank sequences similar to ours (>97\%). An alignment of 260 AOA sequences (223 newly generated sequences, 9 from the reference dataset, 27 environmental sequences from GenBank and Candidatus Nitrosocaldus yellowstonii as an outgroup) was trimmed to the same length (ca. $450 \mathrm{bp}$ ). For AOB, an alignment of 246 sequences (212 newly generated sequences, 16 from the reference dataset, 18 environmental sequences from GenBank and Nitrosococcus oceani as an outgroup) was trimmed to the same length (ca. 432 bp). For nirK-type bacterial denitrifiers, an alignment of 142 sequences (104 newly generated sequences, 25 from the reference dataset, 12 environmental sequences from GenBank and Neisseria gonorrhoeae as an outgroup) was trimmed to the same length (ca. $475 \mathrm{bp}$ ). All alignments were performed with the online version of MAFFT 7 using default parameters (Katoh and Standley 2013).

Phylogenetic analyses were conducted using MEGA version 5.1 (Tamura et al. 2011; http://www.megasoftware.net ) and the Kimura two-parameter model (Kimura 1980). Neighbor-joining (NJ) trees were constructed with 1000 replicates to produce bootstrap values. The Mothur program (Schloss et al. 2009) was used to assign sequences to molecular operational taxonomic units (MOTUs) after calculating Jukes-Kantor pairwise distances with PHYLIP (Felsenstein 1989). Similar sequences of AOA, AOB, and nirK-type denitrifiers were clustered into MOTUs using 90, 95, and $90 \%$ identity thresholds, respectively.

MOTU richness, Shannon and Simpson index, and Hill number were calculated using Primer v6. The MOTU richness is the number of MOTU (phylo-species) per sample. The Shannon index $\left(H^{\prime}\right)$ was calculated by the formula $H^{\prime}=-\sum$ pi ln pi (pi is the relative abundance of the $i^{\text {th }}$ MOTU compared with all MOTUs identified in a sample) and represents a 
measure of diversity, where the greater the value, the greater the sample diversity (values ranging from 0 to $\infty$ ). The Simpson index was calculated as $1-D$, where $\mathrm{D}=\sum(\mathrm{n} / \mathrm{N})^{2}(\mathrm{n}=$ total number of organisms of a MOTU; $\mathrm{N}=$ the total number of organisms of all MOTU). The value of $1-\mathrm{D}$ represents a measure of diversity that is more sensitive to evenness and gives more weigh to dominant species with respect to $H^{\prime} .1-\mathrm{D}$ ranges from 0 to 1 , and the greater the value, the greater the sample diversity. The Hill number was calculated as $\mathrm{N}_{1}=\exp .\left(H^{\prime}\right)$ and represents a measure of diversity more sensitive to rare species. $\mathrm{N}_{1}$ ranges from 0 to $\infty$ where the greater the value, the greater the sample diversity.

Community sampling effort was verified by Coleman rarefaction curves (Coleman 1981) in EstimateS version 9.1 (Colwell 2013; http://purl.oclc.org/estimates ) using individual-based rarefaction curves (Gotelli and Colwell 2001) with clones/sequences considered as units of replication. All newly generated sequences were submitted to the EMBL nucleotide sequence database, and the accession numbers were assigned from LN823729 to LN823950 for AOA, from LN828351 to LN828561 for AOB, and from LN828562 to LN828664 for nirK-type bacterial denitrifiers.

\section{Statistical analyses}

Dependent variables were analyzed by ANCOVA with land-use intensification as a fixed factor and spatial coordinates of the plots (latitude/longitude) as covariables. In this way, we factored out the plotdistance variable, which may have affected responses of the dependent variables, allowing the most rigorous comparison among treatments. To use the spatial coordinates in the ANCOVAs, they were transformed into radians and then standardized.

All data were transformed when necessary to fulfill assumptions of the ANCOVA. The LSD significant difference test was used for comparisons. When assumptions of the ANCOVA were not fulfilled, data were analyzed using the Kruskal-Wallis non-parametric test, followed by Mann-Whitney $U$ post hoc tests. All analyses were performed in SPSS version 21.0 (SPSS Inc., Chicago, IL, USA).

The partial redundancy analysis (pRDA) linear method (ter Braak and Šmilauer 2012) was used, since the length of the gradient of the detrended 
correspondence analysis was less than four. The pRDAs were used to investigate the influence of land use or soil physico-chemical properties (used as explanatory variables) on community composition (relative abundance of MOTUs) of AOA, AOB, and nirK-type denitrifiers (used as response variables). Monte-Carlo permutation tests were performed using 499 random permutations (unrestricted permutation) to determine the statistical significance of relations between explanatory and response variables.

The variation partitioning test (VarPart) by redundancy analysis (RDA) was performed to assess the unique and shared contributions of the degree of land-use intensification and significant soil physico-chemical properties in explaining the community composition of each microbial group studied. The shared partition represents the variation in the response data that could be explained by both explanatory variables. VarPart was performed by applying a model that tested the unique effects of predictors (VarPart-2groups-Conditional effects-tested) with independent stepwise selection of explanatory variables in each of the two groups of predictors (ter Braak and Šmilauer, 2012) and by applying the approach described by Legendre (2008). All multivariate analyses were performed with CANOCO 5 (ter Braak and Šmilauer 2012).

\section{Results}

\section{Effect of land-use intensification on phylogenetic diversity and abundances of $\mathrm{AOA}$ and $\mathrm{AOB}$}

From screening the clone libraries, a total of 221 and 202 positive clones of AOA and AOB were obtained, respectively. For AOA, 58 positive clones were obtained from HI, 92 from LI, and 71 from ZI soils. For AOB, 63, 74, and 65 positive clones were obtained for HI, LI, and ZI, respectively. AOA sequences were grouped in 13 MOTUs (Fig. 1; Online Resource 2: Fig. S1a, b). A total of 7, 11, and 8 MOTUs were retrieved from the soils of HI, LI, and ZI, respectively. All MOTUs were phylogenetically affiliated to uncultured Thaumarchaeota, except for Nitrosotalea_1_AMASS (1) and Nitrosoarchaeum_1_AMASS (4), which were affiliated to Nitrosotalea sp. and Nitrosoarchaeum sp., respectively. All uncultured MOTUs and Nitrosoarchaeum_1_AMASS (4) were affiliated to the thaumarchaeal lineage I.1a, while Nitrosotalea_1_AMASS (1) was affiliated to the I.1a-associated lineage. As shown in the pie charts 
of the NJ tree (Fig. 1), two MOTUs were retrieved exclusively from LI soils (AOA_6_MASS and AOA_7_AMASS), while one (AOA_10_AMASS) was exclusively found in ZI soils. In contrast, Nitrosotalea1_AMASS, AOA_1_AMASS, and AOA_5_AMASS showed ubiquitous behavior. Nitrosotalea1_AMASS was mainly present in HI soils and Nitrosoarchaeum 1 AMASS in HI and LI soils. No significant difference among land-use types was found based on diversity indices and relative abundances (Table 1; Online Resource 2: Fig. S2a). MOTU richness ranged from 4.0 to 6.0 in $\mathrm{HI}$ and ZI soils, respectively (Table 1). The Shannon and the Simpson indices ranged from 0.84 to 1.33 and from 0.42 to 0.60 in $\mathrm{HI}$ and LI, respectively, while the Hill number ranged from 2.48 to 3.91 in $\mathrm{HI}$ and ZI, respectively.

\section{Fig. 1}

Neighbor-joining (NJ) tree of ammonia-oxidizing archaea (AOA) sequences from soil under three levels of land-use intensification: high intensity (HI; maize monoculture), low intensity (LI; extensive grassland), and zero intensity (ZI; agricultural soil left abandoned). $\mathrm{NJ}$ is based on the functional archaeal gene amoA ( $\approx 450 \mathrm{bp}$; Arch-amoAF/Arch-amoAR fragment) and is composed of 223 newly generated sequences plus 9 from a reference dataset and 27 environmental sequences from GenBank (similarity >97\%). The tree is rooted with Candidatus Nitrosocaldus yellowstonii. In the collapsed NJ tree, black triangles represent the 13 archaeal molecular operational taxonomic units (MOTUs) retrieved in the study. The sequences obtained were affiliated to Nitrosotalea sp. (1), Nitrosoarchaeum sp. (4), and uncultured Thaumarchaeota $(2,3,5,6,7,8,9,10,11,12,13)$. For each MOTU, the proportions of sequences retrieved from each land-use type (HI, red; LI, yellow; ZI, green) are shown in the pie charts. Accession numbers of sequences obtained in the present study are shown in Fig. S3S1. Bootstrap values (based on 1000 replicates) are shown at the nodes. The scale bar indicates substitutions per site. Parentheses indicate the classification according to Pester et al. (2011). The name of each MOTU is composed of the name of the closest phylogenetically affiliated group, a serial number, and the acronym of the experimental site. Please refer to the web version of this article for interpretation of the colors in this figure 


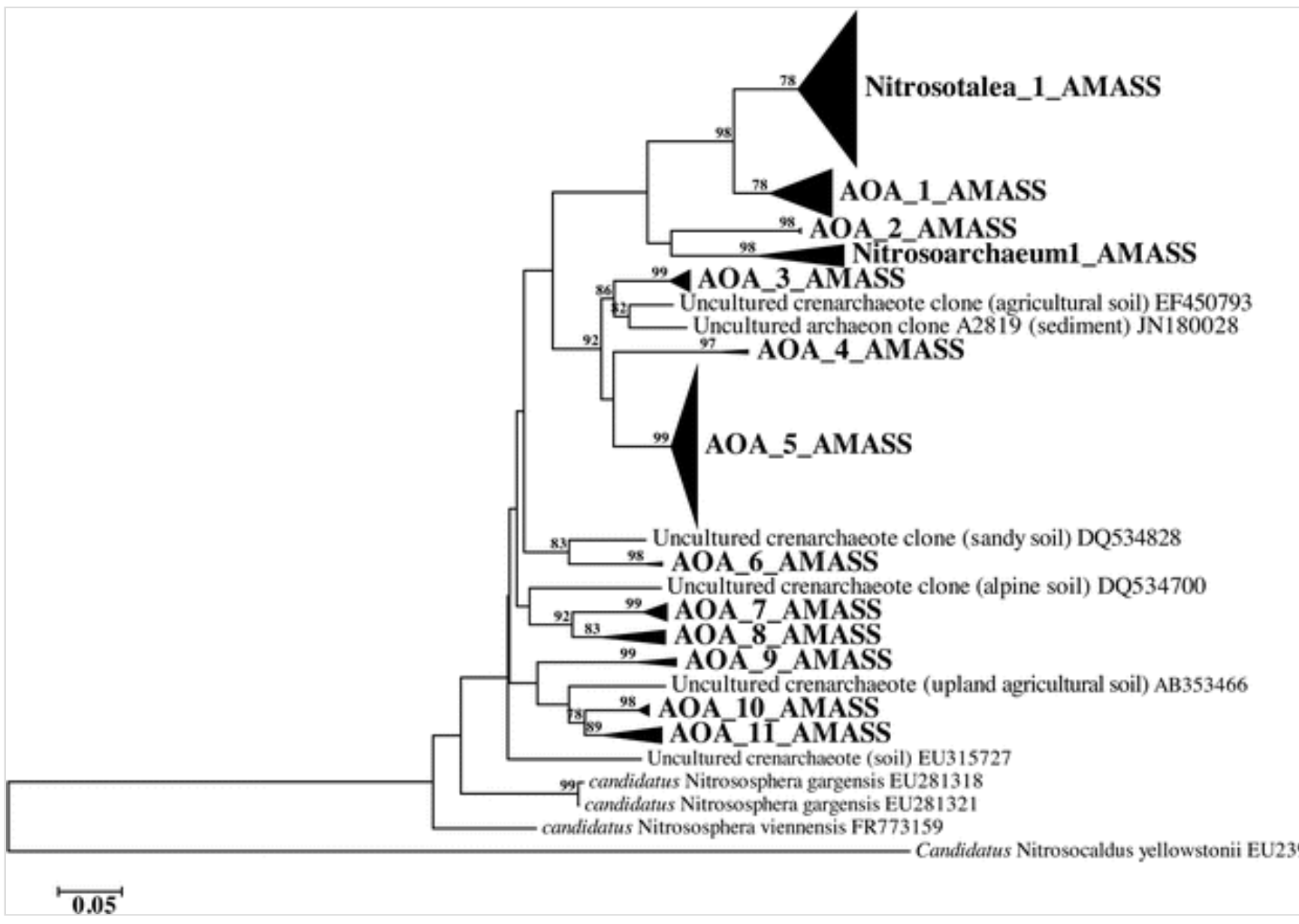

\section{Table 1}

Richness, Shannon index, Hill number, and Simpson index based on molecular oper archaea (AOA), ammonia-oxidizing bacteria (AOB), and nirK-type denitrifier bact intensification: high intensity (HI; maize monoculture); low intensity (LI; extensive abandoned)

\begin{tabular}{|l|c|c|c|c|c|}
\hline Parameter & HI & \multicolumn{1}{|c|}{ LI } & \multicolumn{1}{|c|}{ ZI } & \multicolumn{1}{|c|}{ HI } & \multicolumn{1}{|c|}{ LI } \\
\hline $\begin{array}{l}\text { MOTU } \\
\text { richness }\end{array}$ & $4.00 \pm 1.00^{\mathrm{a}}$ & $5.67 \pm 0.88$ & $6.00 \pm 1.15$ & $3.66 \pm 0.67$ & $5.00 \pm 0.58$ \\
\hline $\begin{array}{l}\text { Shannon } \\
\text { Index }\end{array}$ & $0.84 \pm 0.28$ & $1.33 \pm 0.14$ & $1.29 \pm 0.29$ & $0.85 \pm 0.15$ & $0.89 \pm 0.34$ \\
\hline $\begin{array}{l}\text { Hill } \\
\text { number }\end{array}$ & $2.48 \pm 0.61$ & $3.84 \pm 0.50$ & $3.91 \pm 0.94$ & $\begin{array}{l}2.39 \pm 0.36 \\
\mathrm{a}\end{array}$ & $\begin{array}{l}3.39 \pm 0.15 \\
\mathrm{~b}\end{array}$ \\
\hline $\begin{array}{l}\text { Simpson } \\
(1-D)\end{array}$ & $0.42 \pm 0.14$ & $0.67 \pm 0.04$ & $0.60 \pm 0.13$ & $\begin{array}{l}0.46 \pm 0.78 \\
\mathrm{a}\end{array}$ & $\begin{array}{l}0.63 \pm 0.34 \\
\mathrm{~b}\end{array}$ \\
\hline
\end{tabular}

${ }^{a}$ Values are means $\pm \mathrm{SE}$ of three replicate plots for each land-use type. For each pa letters are statistically different among land-use types according to ANCOVA and the ANCOVA were not fulfilled, data were analyzed using the Kruskal-Wallis nonpost hoc test 
AOB sequences were grouped into 11 MOTUs. A total of five, eight, and eight were retrieved from the soils of HI, LI, and ZI, respectively (Fig. 2; Online Resource 2: Fig. S3a, b). Six out of 11 MOTUs (AOB1_AMASS, AOB2_AMASS, AOB3_AMASS, AOB4_AMASS, AOB5_AMASS, AOB6_AMASS) were phylogenetically affiliated to uncultured AOB, while four (Nitro m_1_AMASS, Nitro_sp_1_AMASS, Nitro_sp_2_AMASS, Nitro_sp_3_AMASS, and Nitro_sp_4_AMASS) were closely related to sequences of cultured isolates of Nitrosospira sp. ( $\beta$ AOB). According to the classification of Purkhold et al. (2000) and Zhang et al. (2009), Nitro_m_1_AMASS and Nitro_sp_3_AMASS fell into cluster 3, while Nitro_sp_1_AMASS and Nitro_sp_4_AMASS fell into cluster 2 and Nitro_sp_2_AMASS into cluster 0. As shown in the pie charts of the NJ tree (Fig. 2), three MOTUs were retrieved exclusively in ZI soils (Nitro m1_AMASS, AOB3_AMASS, AOB5_AMASS), while Nitro_sp_4_AMASS was found exclusively in LI soils. In contrast, AOB1_AMASS, AOB2_AMASS and Nitro_sp_1_AMASS showed ubiquitous behavior. The Hill number and the Simpson index were significantly affected by land-use intensification, with lower values observed in HI than in other land uses (Table 1). MOTU richness ranged from 3.6 to 6.7 in HI and ZI soils, respectively, while the Shannon index ranged from 0.85 to 1.53 in $\mathrm{HI}$ and $\mathrm{ZI}$ soils, respectively. Regarding relative abundances (Online Resource 2: Fig. S2b), only Nitros_sp_1_AMASS (cluster 2) was significantly higher in HI soils than in those of LI soils $(P<0.05)$.

\section{Fig. 2}

Neighbor-joining (NJ) tree of ammonia-oxidizing bacteria (AOB) sequences from soil under three levels of land-use intensification: high intensity (HI; maize monoculture), low intensity (LI; extensive grassland), and zero intensity (ZI; agricultural soil left abandoned). $\mathrm{NJ}$ is based on the functional bacterial gene amoA $(\approx 432 \mathrm{bp} ;$ amoA $1 \mathrm{~F} /$-amo $2 \mathrm{R}$ fragment $)$ and is composed of 212 newly generated sequences plus 16 from a reference dataset and 18 environmental sequences from GenBank. The tree is rooted with Nitrosococcus oceani. In the collapsed NJ tree, black triangles represent the 11 bacterial molecular operational taxonomic units (MOTUs) retrieved in the study. The sequences obtained were affiliated to Nitrosospira sp. $(2,6,7,9,11)$ and uncultured $\mathrm{AOB}(1,3,4,5,8,10)$. For each MOTU, the proportions of sequences from each land-use type (HI, red; LI, yellow; ZI, green) are shown in pie charts. Accession numbers of sequences obtained 
in the present study are shown in Fig. S5S3. Bootstrap values (based on 1000 replicates) are shown at the nodes. The scale bar indicates substitutions per site. Parentheses indicate the classification according to Purkhold et al. (2000). The name of each MOTU is composed of the name of the closest phylogenetically affiliated group (Nitro_m Nitrosospira multiformis; Nitro_sp Nitrosospira sp.), a serial number, and the acronym of the experimental site. Please refer to the web version of this article for the interpretation of the colors in this figure

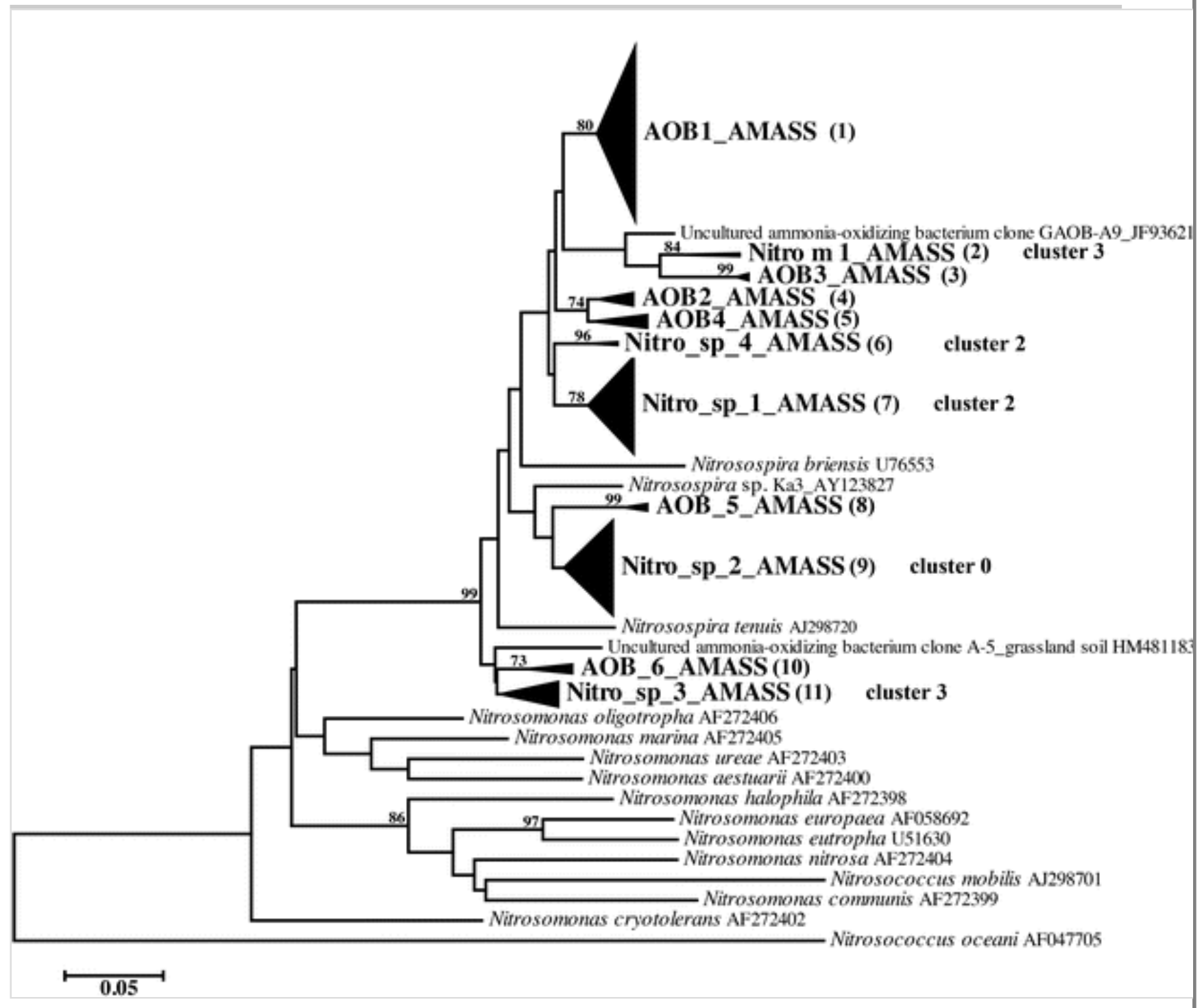

Rarefaction curves showed that the sampling effort was sufficient for both $\mathrm{AOA}$ and $\mathrm{AOB}$, since the accumulation curves reached the asymptote (Online Resource 2: Fig. S4a, b).

Effect of land-use intensification on phylogenetic diversity and abundance of nirK-type denitrifier bacteria

A total of 103 positive clones of nirK-type denitrifier bacteria (nirK) were 
obtained from screening the clone libraries. In detail, 51 and 52 positive clones were obtained from LI and ZI soils, respectively, while from HI soils, despite modifying PCR conditions (e.g., annealing temperature, master mix component, primer and template concentration), no nirK gene fragments were amplified.

NirK-type sequences were clustered in 12 MOTUs (Fig. 3 ; Online Resource 2: Fig. S5). All 12 MOTUs were retrieved in LI soils, whereas only seven were retrieved in ZI soils. It is notable that no nirK sequences were retrieved in HIsoils. All MOTUs were phylogenetically affiliated to uncultured denitrifying bacteria, except for Bradyrhizo_1_AMASS (2) and Mesorhizo_1_AMASS (9), which were affiliated to Bradyrhizobium sp. and Mesorhizobium sp., respectively. As shown in the pie charts of the NJ tree (Fig. 3), five MOTUs (nirK_3_AMASS, nirK_4_AMASS, nirK_5_AMASS, nirK_6_AMASS, and nirK_10_AMASS) related to uncultured nirK were retrieved exclusively in LI. MOTU richness ranged from 0.00 to 6.33 in HI and LI soils, respectively (Table 1). Regarding MOTU richness and diversity indices, significant differences were observed between HI and LI/ZI soils (Online Resource 2: Fig. S2c). The Shannon index, Simpson index, and Hill number ranged from 0.00 to 1.59, from 0.00 to 0.75 , and from 0.00 to 4.93 in HI and LI, respectively (Table

1 ). The relative abundances of nirK-type denitrifier bacteria (Fig S2c Online Resource 2) demonstrated that nirK_4_AMASS and nirK_10_AMASS were significantly higher in LI and ZI than in HI $(P<0.05)$.

\section{Fig. 3}

Neighbor-joining (NJ) tree of nirK-type denitrifier sequences from soil under three levels of land-use intensification: high intensity (HI; maize monoculture), low intensity (LI; extensive grassland), and zero intensity (ZI; agricultural soil left abandoned). $\mathrm{NJ}$ is based on the functional bacterial gene nirK ( $\approx 475 \mathrm{bp}$; nirK1F/nirK5R fragment) and is composed of 104 newly generated sequences plus 25 from a reference dataset and 12 environmental sequences from GenBank. The tree is rooted with Neisseria gonorrhoeae. In the collapsed NJ tree, black triangles represent the 12 bacterial molecular operational taxonomic units (MOTUs) retrieved in the study. The sequences obtained were affiliated to Bradyrhizobium sp. (2), Mesorhizobium sp. (9), and uncultured nirK copper-containing nitrite reductase bacteria $(1,3,4,5$, $6,7,8,10,11,12)$. For each MOTU, the proportions of sequences from each 
land-use type (HI, red; LI, yellow; ZI, green) are shown in pie charts. Accession numbers of sequences obtained in the present study are shown in Fig. S7. Bootstrap values (based on 1000 replicates) are shown at the nodes. The scale bar indicates substitutions per site. The name of each MOTU is composed of the name of the closest phylogenetically affiliated group, a serial number, and the acronym of the experimental site. Please refer to the web version of this article for the interpretation of the colors in this figure AQ3

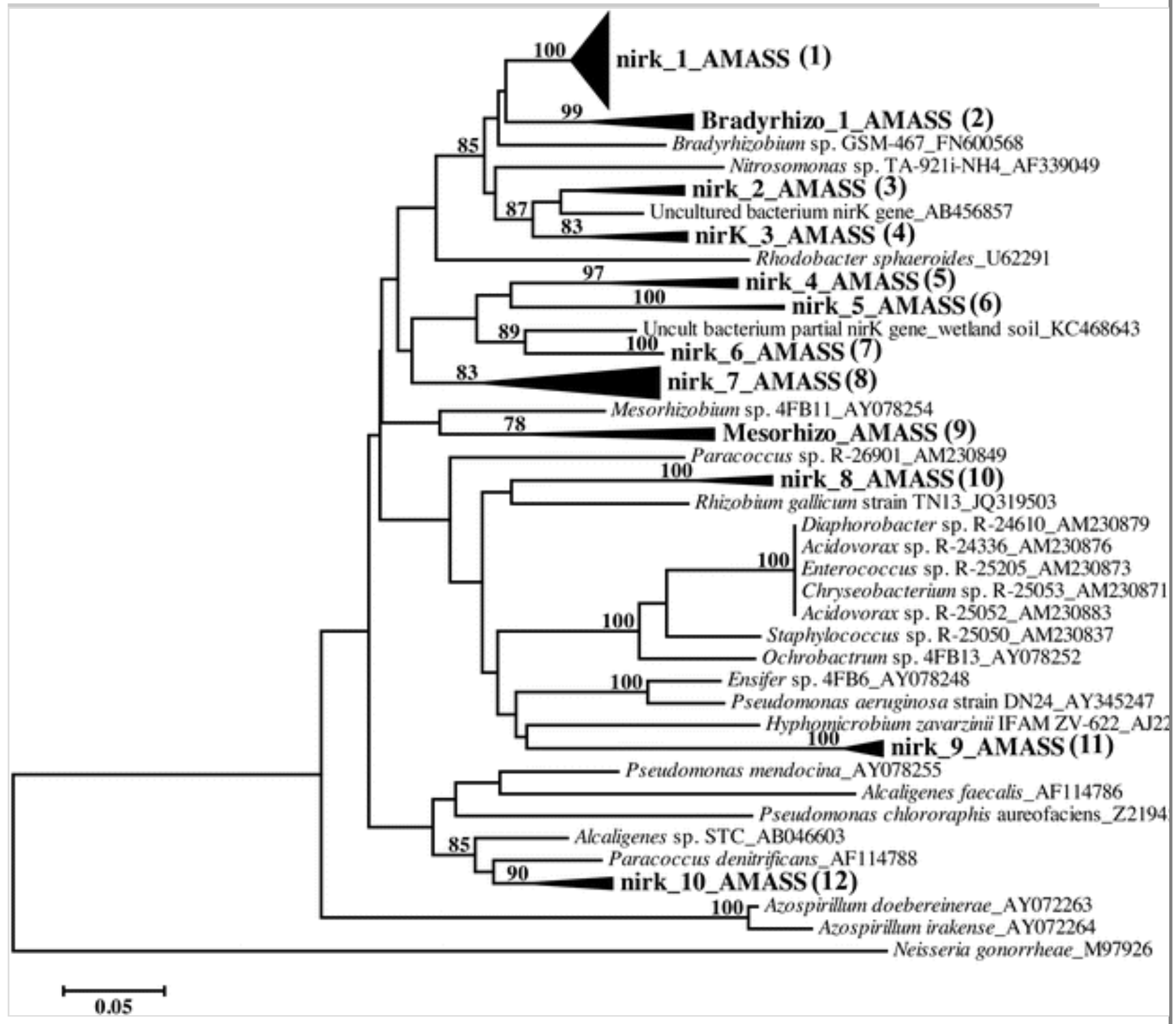

Rarefaction curves showed that the sampling effort was sufficient, since the accumulation curves reached the asymptote (Online Resource 2: Fig. $\mathrm{S} 4 \mathrm{c})$. 


\section{$\mathrm{AOA}$ and $\mathrm{AOB}$}

The pRDA showed that land-use intensification significantly affected AOA and AOB community composition (Fig. 4a, b). Regarding AOA, the first two axes explained $32.1 \%$ (Fig. 4a), and the Monte-Carlo permutation test indicated that the AOA community in ZI differed from those in the other land uses $(P=0.036)$. Specifically, AOA_10_AMASS was preferentially associated with ZI, while AOA_6_AMASS and AOA_7_AMASS were associated with LI and Nitrosotalea_1_AMASS with HI. Similarly, the AOB community in ZI differed from those in the other land uses $(P=0.020)$ (Fig. $4 b)$. In this case, the first two axes explained $46.2 \%$ of the total variance. Specifically, Nitro m_1_AMASS, AOB_3_AMASS, and AOB_5_AMASS were preferentially associated with ZI, while AOB_4 (5) and Nitro_sp4_AMASS were associated with HI and LI, respectively.

\section{Fig. 4}

Partial redundancy analysis (pRDA) biplots based on relative abundances of molecular operational taxonomic units (MOTUs) of a ammonia-oxidizing archaea (AOA), b ammonia-oxidizing bacteria (AOB), and c nirK-type denitrifier bacteria, used as response variables, and three levels of land-use intensification, used as environmental variables. Land uses were high intensity (HI; maize monoculture), low intensity (LI; extensive grassland), and zero intensity (ZI; agricultural soil left abandoned). Spatial coordinates of the plots (latitude/longitude) were used as covariables. The sum of the variance explained by the 1 st and 2nd axes together accounted for 32.1, 46.2, and $46.3 \%$ of the total variance of $\mathbf{a}, \mathbf{b}$, and $\mathbf{c}$, respectively. The MonteCarlo permutation test showed that AOA, AOB, and nirK-type denitrifier compositions were significantly different between ZI and HI/LI $(P=0.036$, $P=0.020$, and $P=0.016$, respectively). In the case of nirK-type denitrifiers, no sequences were retrieved in HI, and the Monte-Carlo permutation test showed a difference between HI and LI $(P=0.002)$. The name of each MOTU is composed of the name of the closest phylogenetically affiliated group, a serial number, and the acronym of the experimental site. Please refer to the web version of this article for the interpretation of the colors in this figure

\section{(a)}

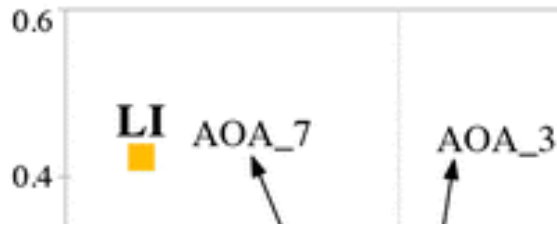




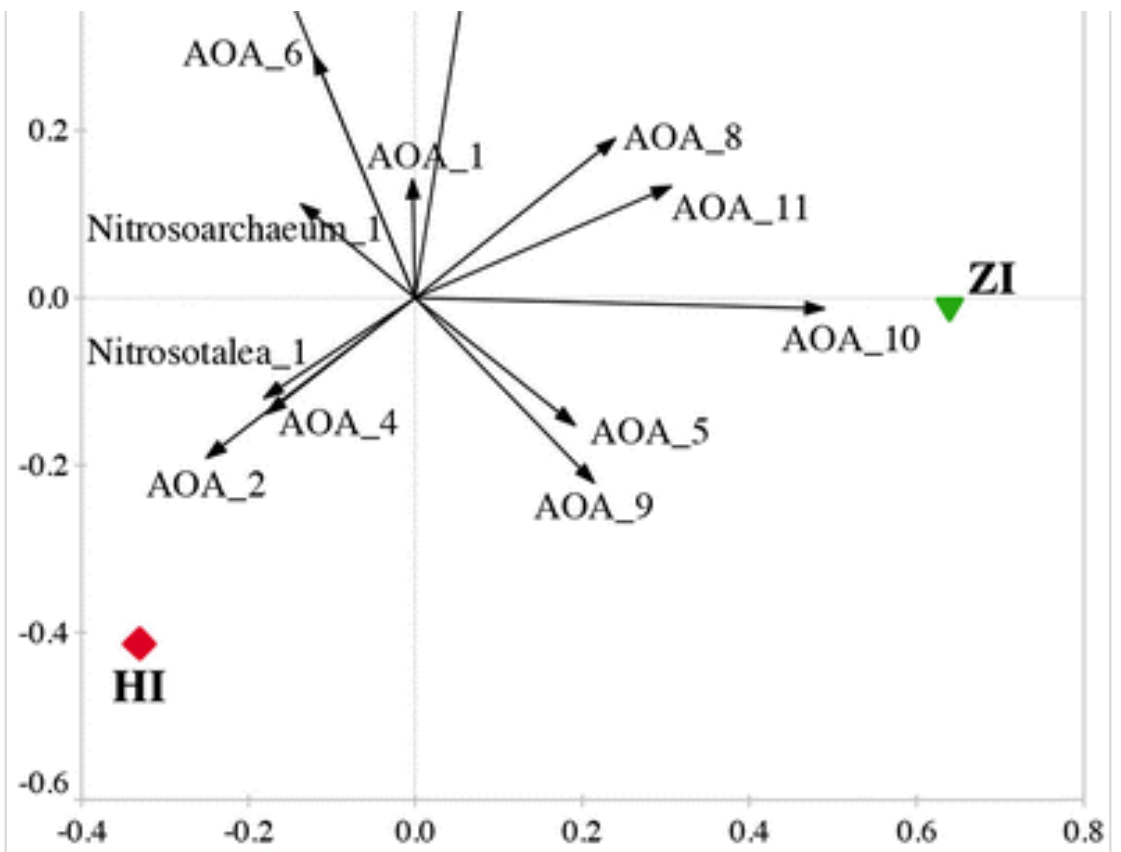

(b)

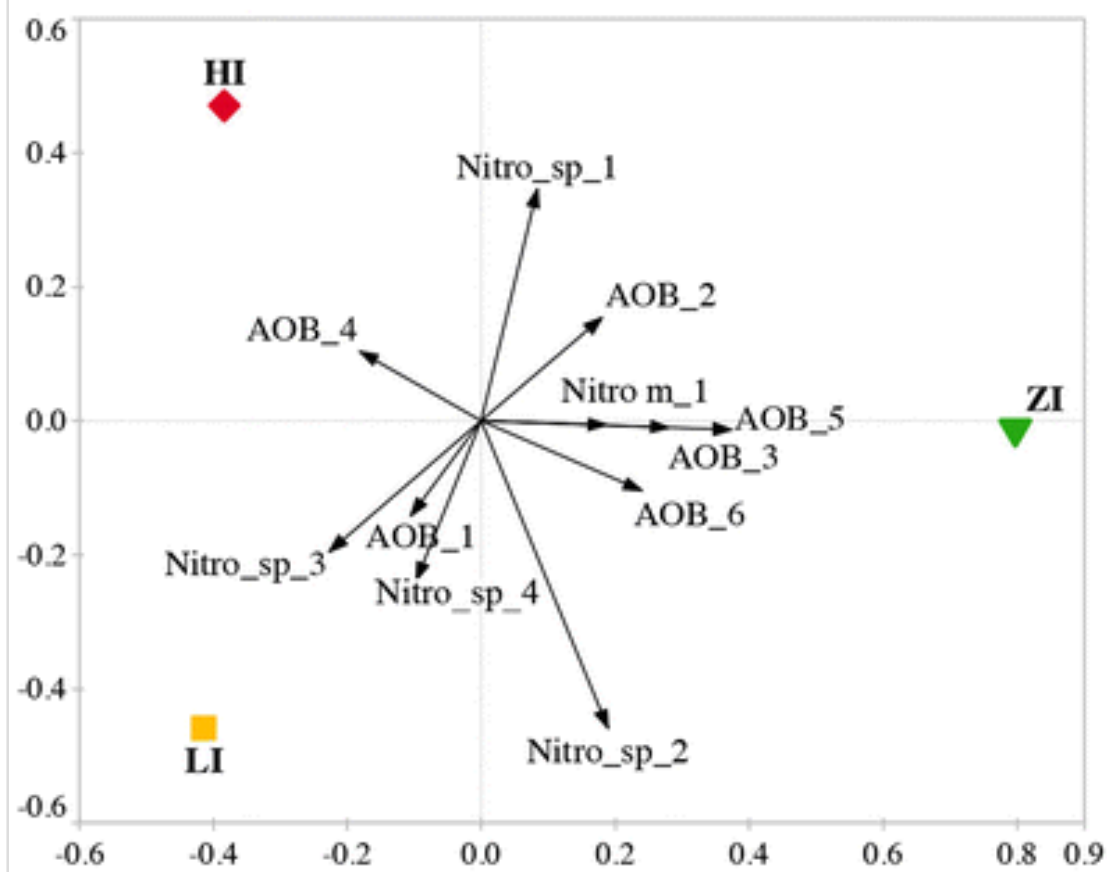

(c)

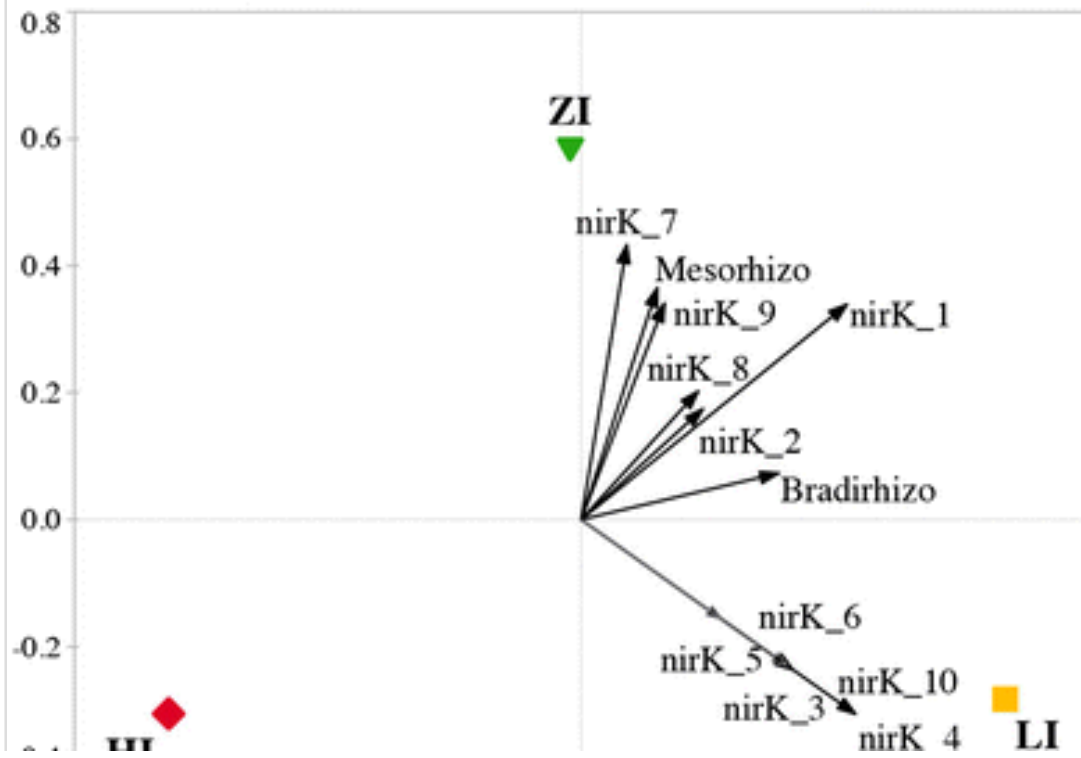




\begin{tabular}{|c|c|c|c|c|c|c|c|c|}
\hline \multirow{2}{*}{\multicolumn{2}{|c|}{$-0.4 \mid \mathbf{n I}$}} & & & & \multicolumn{4}{|c|}{ e.Proofing } \\
\hline & & & & & & & - & \\
\hline-0.8 & -0.6 & -0.4 & -0.2 & 0.0 & 0.2 & 0.4 & 0.6 & 0.8 \\
\hline
\end{tabular}

The pRDA showed that soil physico-chemical properties significantly affected AOA and AOB community composition (Fig. 5a). The first two axes explained 40.4 and $45.0 \%$ of the total variance for AOA and AOB, respectively (Fig. 5a). ExchCa and the clay percentage of the soil mineral component revealed significant soil physico-chemical drivers of AOA composition (Monte-Carlo permutation test and stepwise selection $P=0.014$ and $P=0.032$, respectively), while bulk density and ExchCa drove AOB composition (Monte-Carlo permutation test and stepwise selection $P=0.014$ and $P=0.036$, respectively) (Fig. 5b).

\section{Fig. 5}

Partial redundancy analysis (pRDA) biplots based on relative abundances of MOTUs of a ammonia-oxidizing archaea (AOA), b ammonia-oxidizing bacteria (AOB), and c nirK-type denitrifier bacteria, used as response variables, and soil physico-chemical parameters, used as environmental variables. Spatial coordinates of the plots (latitude/longitude) were used as covariables. The sum of the variance explained by the 1 st and 2 nd axes together accounted for $40.4,45.0$, and $49.6 \%$ of the total variance of $\mathbf{a}, \mathbf{b}$, and c, respectively. Bold red arrows show the significant soil physicochemical parameters selected after the Monte-Carlo permutation test and stepwise selection $(P \leq 0.05)$. Significant soil physico-chemical parameters were exchangeable calcium (ExchCa) and the clay percentage of the soil texture for the AOA community, ExchCa and bulk density (BD) for the AOB community, and ammonium $\left(\mathrm{NH}_{4}^{+}\right)$, the silt percentage of the soil mineral component, and exchangeable potassium (ExchK) for the nirK-type denitrifiers. The name of each MOTU is composed of the name of the closest phylogenetically affiliated group, a serial number, and the acronym of the experimental site. Please refer to the web version of this article for the interpretation of the colors in this figure

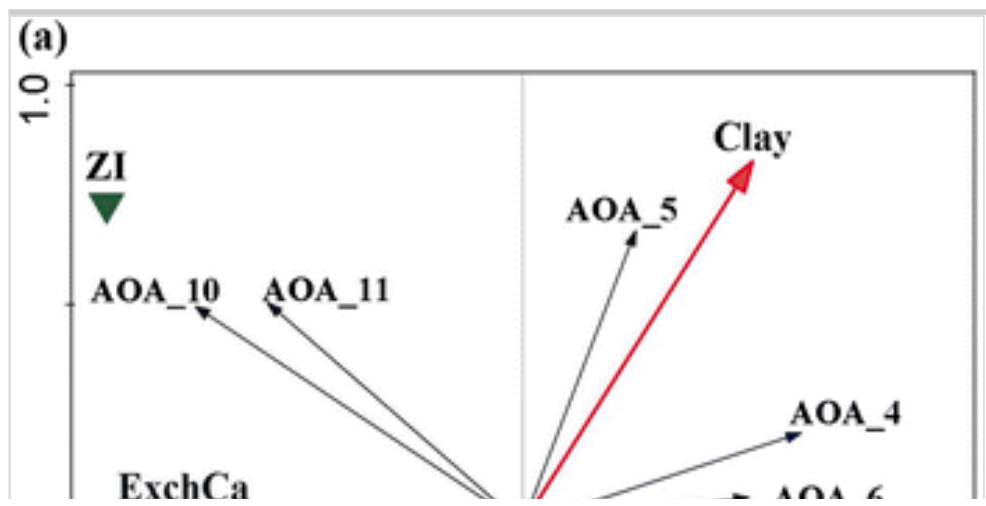




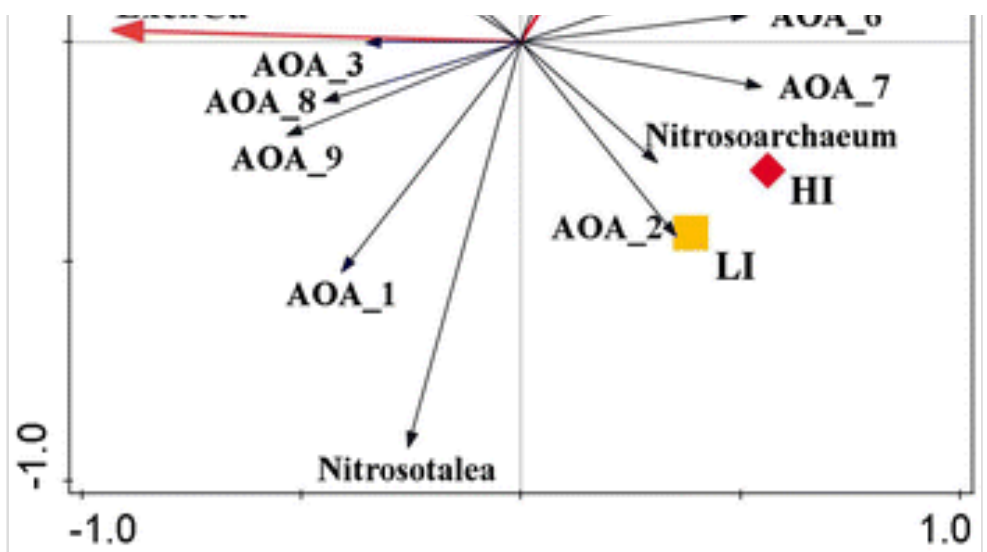

(b)

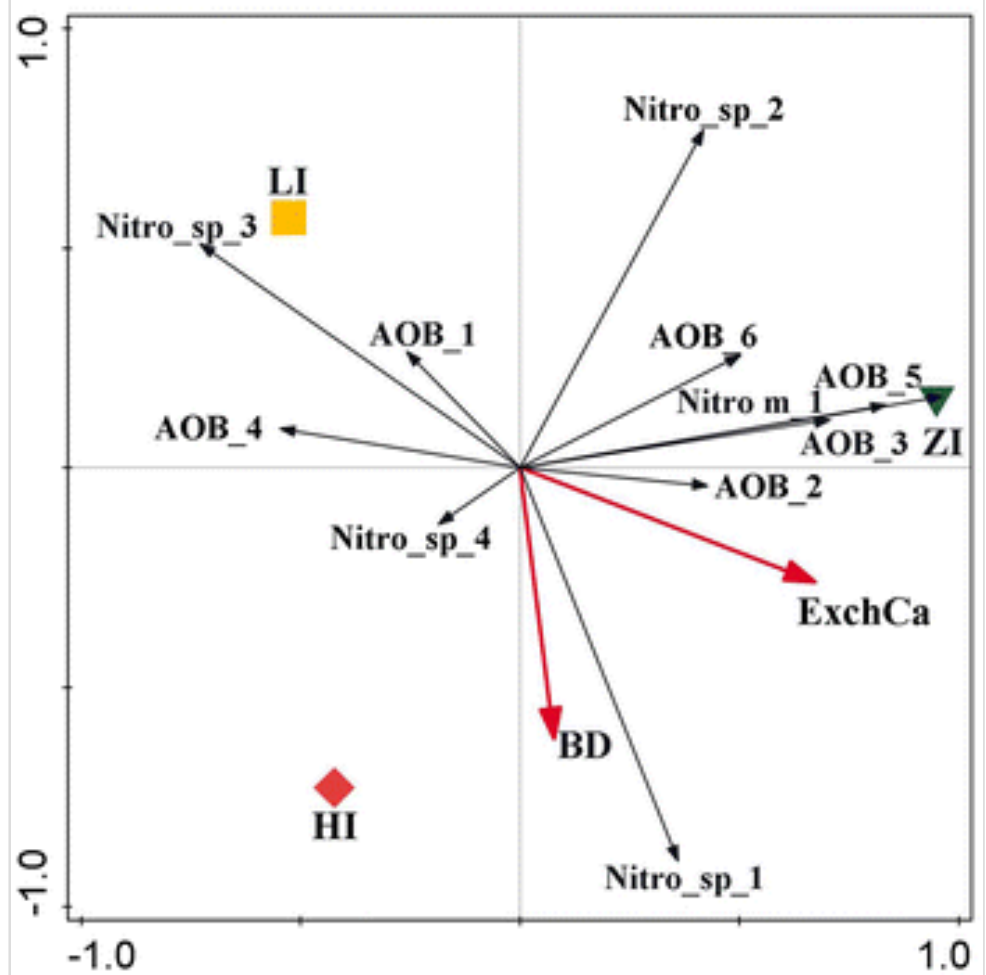

(c)

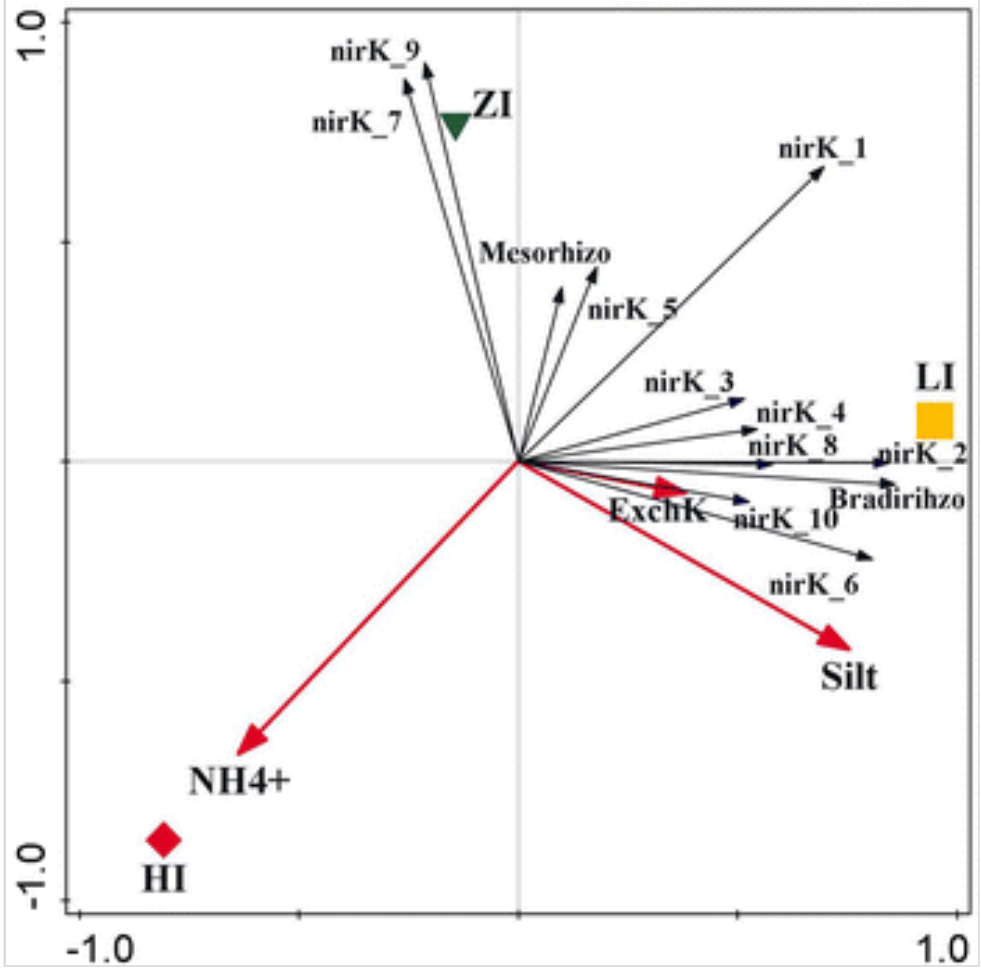


The negative value of the shared variation fraction in AOA indicates that the joint explanatory effect of the two groups of variables, namely, landuse intensification and physico-chemical properties, is stronger than the sum of their marginal effects (Table 2). By contrast, VarPart of AOB composition showed that land-use intensification contributed more than soil physico-chemical properties to the shaping of the community.

\section{Table 2}

Results of variation partitioning by redundancy analysis (RDA) on the significant drivers of community composition of ammonia-oxidizing archaea (AOA), ammoniaoxidizing bacteria (AOB), and nirK-type denitrifier bacteria (nirK) in soils under different degrees of land-use intensification: high intensity (HI; maize monoculture); low intensity (LI; extensive grassland), and zero intensity (ZI; agricultural soil left abandoned)

AQ4

\begin{tabular}{|c|c|c|c|}
\hline $\begin{array}{l}\text { Soil microbial } \\
\text { community }\end{array}$ & Driver & $d f$ & $\begin{array}{c}\text { Explained variance } \\
(\%)\end{array}$ \\
\hline \multirow{5}{*}{$\mathrm{AOA}$} & $\mathrm{a}$ & 2 & 36.4 \\
\hline & $\mathrm{b}(\mathrm{ExchCa}+\mathrm{clay})$ & 2 & 70.0 \\
\hline & $c(a$ and $b)$ & - & -6.4 \\
\hline & Total explained & 4 & 100.0 \\
\hline & Total variation & 8 & - \\
\hline \multirow{5}{*}{$\mathrm{AOB}$} & $\mathrm{a}$ & 2 & 66.6 \\
\hline & $\mathrm{b}(\mathrm{ExchCa}+\mathrm{BD})$ & 2 & 28.2 \\
\hline & $c(a$ and $b)$ & - & 5.2 \\
\hline & Total explained & 4 & 100.0 \\
\hline & Total variation & 8 & - \\
\hline \multirow{5}{*}{ nirK } & $\mathrm{a}$ & 2 & 14.9 \\
\hline & $\stackrel{b}{(\text { Silt }}+\mathrm{NH}_{4}^{+}+$ExchK $)$ & 3 & 43.4 \\
\hline & $c(a$ and $b)$ & - & 41.8 \\
\hline & Total explained & 5 & 100.0 \\
\hline & Total variation & 8 & - \\
\hline
\end{tabular}

The unique contributions of drivers $(\mathrm{a}=$ land-use intensification; $\mathrm{b}=$ soil 
physico-chemical parameters) and mutual overlaps (c) are shown. Variation was adjusted as described in Legendre (2008)

Exch Ca exchangeable calcium, $\mathrm{BD}$ bulk density, $\mathrm{NH}_{4}{ }^{+}$ammonium, ExchK exchangeable potassium

\section{Effect of land-use intensification and soil physico- chemical properties on the community structure of nirK- type denitrifier bacteria}

The pRDA showed that land-use intensification and soil physico-chemical properties significantly affected nirK-type community composition (Figs. $4 \mathrm{c}$ and $5 \mathrm{c}$ ). Regarding land-use intensification, the first two axes explained $46.3 \%$ of the total variance, and the Monte-Carlo permutation test indicated that the nirK-type community in HI differed from those in the other land uses $(P=0.050)$, since no nir $K$-type gene fragments were amplified in the former. In addition, nirK-type composition in LI differed from that in ZI $(P=0.016)$. Specifically, five MOTUs affiliated with uncultured nirK-denitrifying bacteria (nirK_3_AMASS, nirK_4_AMASS, nirK_5_AMASS, nirK_6_AMASS, and nirK_10_AMASS) were preferentially associated with LI.

Regarding soil physico-chemical properties, the first two axes explained $49.6 \%$ of the total variance (Fig. $5 \mathrm{c}$ ), and according to the Monte-Carlo permutation test and stepwise selection, the silt percentage of the soil mineral component $(P=0.020), \mathrm{NH}_{4}{ }^{+}(P=0.026)$, and ExchK $(P=0.050)$ were the significant drivers.

VarPart of the nirK-type composition showed that most of the contribution was shared between land-use intensification and $\mathrm{NH}_{4}^{+}$(Table 2).

\section{Discussion}

This study provides the first insights on the impact of land-use intensification and soil properties in shaping the composition of N-cycling communities in Mediterranean peaty soils drained for agricultural purposes. A continuous maize cropping system (HI) was compared to an extensive grassland (LI) and to an agricultural soil left abandoned for 15 years (ZI). Phylogenetic and multivariate analyses showed that (i) the majority of sequences of AOA and AOB grouped within the Nitrosotalea and Nitrosospira clusters, respectively; (ii) uncultured denitrifying bacteria 
were unique to our soil; (iii) land-use intensification shaped the composition of N-cycling communities; (iv) ammonia-oxidizing communities were driven by the clay percentage of the soil mineral component (AOA), bulk density (AOB), and exchangeable calcium (both AOA and AOB); and (v) nirK-type bacterial denitrifiers were shaped by the silt percentage of the soil mineral component, $\mathrm{NH}_{4}{ }^{+}$, and exchangeable potassium.

\section{Effect of land-use intensification and soil properties on phylogenetic diversity and abundances of AOA and AOB}

Phylogenetic analyses of AOA showed that most sequences were grouped in Nitrosotalea, while some were grouped in the

Nitrosoarcheum/Nitrosopumilus cluster. This is similar to previous findings obtained from soils of peatlands, forests, paddies, and grasslands

(Herrmann et al. 2012; Puglisi et al. 2014; Zhao et al. 2015) and contrasts with other studies that observed the dominance of Nitrososphaera in agricultural soils and grasslands (He et al. 2007; Shen et al. 2008; Di et al. 2009; Chen et al. 2014). All other sequences grouped in clusters related to the lineages $1.1 \mathrm{a}$ and $1.1 \mathrm{a}$-associated, which are often retrieved in agricultural acidic soils (Zhalnina et al. 2012; Zhang et al. 2012). The presence of sequences with similarities to Nitrosotalea devanaterra increases the number of studies that reported the presence of this microorganism in peaty soils and strengthens its role in the explanation of ammonia oxidation processes in acidic soils (Herrmann et al. 2012; Puglisi et al. 2014). Although no differences were found among the diversity indices of the three land-use types, their values fell within previously observed ranges (Xu et al. 2012; Wang et al. 2014; Zhao et al. 2015).

Phylogenetic analyses of AOB showed that most sequences were affiliated with Nitrosospira clusters, whereas other sequences showed no similarity with any known cultivated species. This finding agrees with previous studies that demonstrated a clear dominance of Nitrosospira-like sequences in agricultural soils (Bruns et al. 1999; Phillips et al. 2000; He et al. 2007; Chen et al. 2014). Across all three land-use types, most sequences were affiliated with cluster 2 (Nitro_sp_1_AMASS and Nitro_sp_4_AMASS), which is commonly retrieved in acidic soils, such as under forests and peatlands (Stephen et al. 1996; Kowalchuk et al. 2000; Herrmann et al. 2012). In LI and ZIsoils, we found several sequences affiliated with cluster 0 (Nitro_sp_2_AMASS) since they are typically 
retrieved in undisturbed and unfertilized grasslands and high $\mathrm{NH}_{3}$ concentrations inhibit their growth (Kowalchuk et al. 2000; Webster et al. 2002; Tourna et al. 2010). In addition, as in managed soils, sequences affiliated with Nitrosospira cluster 3 (Nitro m_1_AMASS and Nitro_sp_3_AMASS) were mainly retrieved in HI and LI soils (Kowalchuk et al. 2000; Phillips et al. 2000; He et al. 2007; Shen et al. 2008). Values of the Shannon index fell within previously observed ranges (Zhao et al. 2015 ), and, in agreement with other studies (Phillips et al. 2000; Carney et al. 2004), it did not change between uncultivated and cultivated soils. In contrast, the significantly lower value of the Simpson index and Hill number in HI soils with respect to LI/ZI soils demonstrated that land-use intensification determined a decrease of abundance of both dominant and rare species.

Finally, both groups of ammonia oxidizers had lower MOTU richness than those detected in other studies (Carney et al. 2004; Zhao et al. 2015), suggesting that the low $\mathrm{pH}$ and high contents of humic acids and organic $\mathrm{C}$ in peaty soils have a selective pressure on the richness of these microbial groups (Gubry-Rangin et al., 2010; Herrmann et al. 2012; Yao et al. $2013)$.

AQ5

\section{Effect of land-use intensification and soil properties on phylogenetic diversity and abundance of nirK-type denitrifier bacteria}

Similar to results of Priemé et al. (2002) for nirS-type denitrifier bacteria, the absence of nirK-type bacterial sequences in HI may be due to HI having the lowest $\mathrm{pH}$ of the land-use types studied. It is worth to specify that the absence of nirK-type bacterial sequences in HI does not necessarily imply that the denitrification process is inhibited. Denitrifying microorganisms may have nirS or nirK gene, and they are mutually exclusive and functionally redundant. The niche segregation between the two different types of nitrite reductases (nirS and nirK) has been widely reported to be linked to the differential effect of the soil physico-chemical properties on the two genes even at farm scale (Philippot et al. 2007; Enwall et al. 2010).

AQ6

Phylogenetic analyses of the nirK-type denitrifier bacterial sequences 
retrieved showed that most sequences in LI and ZI were grouped in uncultured denitrifying bacteria mainly found in acidic soils. These sequences, similar to those previously detected in paddy and agricultural soils (Yoshida et al. 2009; Pastorelli et al. 2011, 2013), showed a high similarity with Rhizobiales (Bradyrhizobiaceae and Phyllobacteriaceae). The sequences belonging to nirK_2_AMASS, nirK_4_AMASS, and nirK 5_AMASS were not similar to any other sequences available in the GenBank database, indicating that they were unique to our soil.

\section{Effect of land-use intensification and soil physico- chemical properties on the community composition of $\mathrm{AOA}$ and $\mathrm{AOB}$}

Our study showed that land-use intensification shaped the soil community composition of both AOA and AOB. Specifically, both community compositions in ZI differed from those occurring in the more intensive agrosystems. This finding agrees with observations in a wide variety of soils where the community composition of ammonia oxidizers in arable land and improved grasslands are clustered together and differ from those under less-intensive land uses (Bruns et al. 1999; Philippot et al. 20007; He et al. 2007; Yao et al. 2013 ). Among soil properties, clay percentages of soil texture and bulk density were significant drivers of AOA and AOB community composition, respectively. This agrees with several studies that examined ammonia-oxidizing communities across agricultural soils and demonstrated that soil texture, aggregate size, and clay content affect the composition of N-cycling microbes (i.e., clay fractions in soils can form microaggregates and macroaggregates and provide microaerophilic or anaerobic conditions that are propitious for $\mathrm{N}$-cycling microbial communities) (Wessén et al. 2011; Pereira e Silva et al. 2012; Zhalnina et al. 2012; de Gannes et al. 2014). Similar to observations of Yao et al. (2013), ExchCa was also found to be a significant driver of both ammoniaoxidizing communities. This parameter may affect microbes by changing soil aggregation, boosting bridges between charged clay particles and humic acids (Muneer and Oades, 1989), and by increasing the nitrification potential (de Gannes et al. 2014). Based on VarPart, soil physico-chemical properties and land-use intensification were detected as major factors shaping the community composition of AOA and AOB, respectively. Concerning AOB, this agrees with previous observations in a wide soil survey (Yao et al. 2013). 


\section{Effect of land-use intensification and soil physico- chemical properties on the community structure of nirK- type denitrifier bacteria}

Land-use intensification affected the community composition of nirK, since no nirK sequences were retrieved in HI soils and the community compositions in LI and ZI soils differed. Along with these findings, previous studies reported a strong impact from tillage and fertilization on nirK community composition and a strong decrease in nirK-gene copy numbers due to land-use intensification and the use of nitrate fertilizers (Hallin et al. 2009; Smith et al. 2010; Dandie et al. 2011; Pastorelli et al. 2013 ). In this regard, the absence of nirK-type denitrifers in the HI land use does not necessarily imply a reduction of the denitrification activity since changes in the community composition of nirK denitrifiers were demonstrated not to be strongly correlated with changes in the denitrification activity (Wertz et al. 2009; Yu et al. 2014).

Regarding soil properties, in agreement with previous studies on agricultural soils and forests (Pastorelli et al. 2011), silt percentage of the soil mineral component was a significant driver of nirK community composition. Moreover, soil $\mathrm{NH}_{4}^{+}$concentration was negatively correlated with nirK relative abundances since the vectors representing the relative abundances of the MOTUs of AOA, AOB, and nirK-type denitrifiers (i.e., response variables) describe an angle $>90^{\circ}$ with the vector representing the explanatory variable $\mathrm{NH}_{4}{ }^{+}$. In addition, soil $\mathrm{NH}_{4}{ }^{+}$concentration was found to be the major driver of nirK community composition, similarly to the observations of Szukics et al. (2010) and Kastl et al. (2015). Based on VarPart, we can assert that soil properties (namely, silt, $\mathrm{NH}_{4}^{+}$, and ExchK) are the primary determinants of nirK community composition, which agrees with observations in agricultural soils by Pastorelli et al. (2011). AQ9

Since no information was previously available about the impacts of landuse intensification on the composition of N-cycling communities in Mediterranean peaty soils, our characterization of ammonia-oxidizing microbes and denitrifiers and the definition of their major drivers in shaping such communities are of great value. In such regard, understanding the drivers affecting $\mathrm{N}$-cycling communities of Mediterranean peatlands 
can be critical to develop appropriate agricultural strategies aiming to optimize the management of soil microbes in order to enhance the efficiency of $\mathrm{N}$ fertilization by reducing $\mathrm{N}$ losses. Future work should also focus on understanding the changes of the community composition and activity of nirS denitrifiers that are shown to be mutually exclusive with nirK in several environments.

\section{Acknowledgments}

This work represents a part of VC's Ph.D. thesis, which was funded by the Scuola Superiore Sant'Anna, Pisa, Italy. The work was also supported by the "Consorzio di Bonifica Versilia-Massaciuccoli" and the "Regione Toscana" ("Restoration of a Mediterranean Drained Peatland"https://sites.google.com/site/restomedpeatland/home ).

\section{Electronic supplementary material}

\section{Online resource 1}

(DOCX $477 \mathrm{~kb})$

Online resource 2

(DOCX $4307 \mathrm{~kb})$

\section{References}

Alef K., Nannipieri P (1995) Methods in applied soil microbiology and biochemistry. Academic press

Andert J, Wessén E, Börjesson G, Hallin S (2011) Temporal changes in abundance and composition of ammonia-oxidizing bacterial and archaeal communities in a drained peat soil in relation to $\mathrm{N}_{2} \mathrm{O}$ emissions. J Soils Sediments 11:1399-1407

Avrahami S, Bohannan BJ (2007) Response of Nitrosospira sp strain AF-like ammonia oxidizers to changes in temperature soil moisture content and fertilizer concentration. Appl Environ Microbiol 73:11661173 
Bardgett RD, Usher MB, Hopkins DW (2005) Biological diversity and function in soils. Cambridge University Press Cambridge

Bruns MA, Stephen JR, Kowalchuk GA, Prosser JI, Paul EA (1999) Comparative diversity of ammonia oxidizer 16S rRNA gene sequences in native, tilled, and successional soils. Appl Environ Microbiol 65:2994-3000

Carney KM, Matson PA, Bohannan BJ (2004) Diversity and composition of tropical soil nitrifiers across a plant diversity gradient and among land-use types. Ecol Lett 7:684-694

Chen X, Zhang LM, Shen JP, Wei WX, He JZ (2011) Abundance and community structure of ammonia-oxidizing archaea and bacteria in an acid paddy soil. Biol Fertil Soils 47:323-331

Chen YL, Hu HW, Han HY, Du Y, Wan SQ, Xu ZW, Chen BD (2014) Abundance and community structure of ammonia-oxidizing archaea and bacteria in response to fertilization and mowing in a temperate steppe in Inner Mongolia. FEMS Microbiol Ecol 89:67-79

Ciccolini V, Bonari E, Pellegrino E (2015) Land-use intensity and soil properties shape the composition of fungal communities in Mediterranean peaty soils drained for agricultural purposes. Biol Fertil Soils 51:719-731. doi: 10.1007/s00374-015-1013-4

Coleman BD (1981) On random placement and species-area relations. Math Biosci 54:191-215

Colwell RK (2013) EstimateS: statistical estimation of species richness and shared species from samples Version 9 and earlier User's Guide and application. http://purl.oclc.org/estimates . Accessed 26 March 2015

Dandie CE, Wertz S, Leclair CL, Goyer C, Burton DL, Patten CL, Zebarth BJ, Trevors JT (2011) Abundance, diversity and functional gene expression of denitrifier communities in adjacent riparian and agricultural zones. FEMS Microbiol Ecol 77:69-82

De Boer W, Kowalchuk GA (2001) Nitrification in acid soils: micro- 
organisms and mechanisms. Soil Biol Biochem 33:853-866

de Gannes V, Eudoxie G, Hickey WJ (2014) Impacts of edaphic factors on communities of ammonia-oxidizing archaea, ammonia-oxidizing bacteria and nitrification in tropical soils. PLoS One 9:e89568

Delmont TO, Francioli D, Jacquesson S, Laoudi S, Mathieu A, Nesme J, Ceccherini MT, Nannipieri P, Simonet P, Vogel TM (2014) Microbial community development and unseen diversity recovery in inoculated sterile soil. Biol Fertil Soils 50:1069-1076

de Vries W, Leip A, Reinds GJ, Kros J, Lesschen JP, Bouwman AF (2011) Comparison of land nitrogen budgets for European agriculture by various modeling approaches. Environ Pollut 159:3254-3268

Di HJ, Cameron KC, Shen JP, Winefield CS, Callaghan MO, Bowatte S, He JZ (2009) Nitrification driven by bacteria and not archaea in nitrogen-rich grassland soils. Nat Geosci 2:621-624 Enwall K, Throbäck IN, Stenberg M, Söderström M, Hallin S (2010) Soil resources influence spatial patterns of denitrifying communities at scales compatible with land management. Appl Environ Microbiol 76: 2243-2250

Felsenstein J (1989) PHYLIP_Phylogeny Inference Package (Version 32). Cladistics 5:164-166

Francis CA, Roberts KJ, Beman JM, Santoro AE, Oakley BB (2005) Ubiquity and diversity of ammonia-oxidizing archaea in water columns and sediments of the ocean. Proc Natl Acad Sci U S A 102:1468314688

Gotelli NJ, Colwell RK (2001) Estimating species richness Frontiers in measuring biodiversity. Oxford University Press, New York

Gubry-Rangin C, Nicol GW, Prosser JI (2010) Archaea rather than bacteria control nitrification in two agricultural acidic soils. FEMS Microbiol Ecol 74:566-574

Hallin S, Jones CM, Schloter M, Philippot L (2009) Relationship 
between N-cycling communities and ecosystem functioning in a 50year-old fertilization experiment. ISME J 3:597-605

Hayatsu M, Tago K, Saito M (2008) Various players in the nitrogen cycle: diversity and functions of the microorganisms involved in nitrification and denitrification. Soil Sci Plant Nutr 54:33-45

He JZ, Shen JP, Zhang LM, Zhu YG, Zheng YM, Xu MG, Di H (2007) Quantitative analyses of the abundance and composition of ammoniaoxidizing bacteria and ammonia-oxidizing archaea of a Chinese upland red soil under long-term fertilization practices. Environ Microbiol 9:2364-2374

Herrmann M, Hädrich A, Küsel K (2012) Predominance of thaumarchaeal ammonia oxidizer abundance and transcriptional activity in an acidic fen. Environ Microbiol 14:3013-3025

IPCC (2006) 2006 IPCC agriculture, forestry and other land uses. In: Eggleston HS, Buendia L, Miwa K, Ngara T, Tanabe K (eds) Guidelines for National Greenhouse Gas Inventories (volume 4) prepared by the National Greenhouse Gas Inventories Programme. IGES, Japan Hayama, Kanagawa

AQ11

Jiang X, Hou X, Zhou X, Xin X, Wright A, Jia Z (2015) pH regulates key players of nitrification in paddy soils. Soil Biol Biochem 81:9-16

Kastl EM, Schloter-Hai B, Buegger F, Schloter M (2015) Impact of fertilization on the abundance of nitrifiers and denitrifiers at the rootsoil interface of plants with different uptake strategies for nitrogen. Biol Fertil Soils 51:57-64

Katoh K, Standley DM (2013) MAFFT multiple sequence alignment software version 7: improvements in performance and usability. Mol Biol Evol 30:772-780

Khan SA, Mulvaney RL, Ellsworth TR, Boast CW (2007) The myth of nitrogen fertilization for soil carbon sequestration. J Environ Qual $36: 1821-1832$ 
Kimura M (1980) A simple method for estimating evolutionary rates of base substitutions through comparative studies of nucleotide sequences. J Mol Evol 16:111-120

Kowalchuk GA, Stephen JR (2001) Ammonia-oxidizing bacteria: a model for molecular microbial ecology. Annu Rev Microbiol 55:485529

Kowalchuk GA, Stienstra AW, Heilig GHJ, Stephen JR, Woldendorp JW (2000) Molecular analysis of ammonia-oxidising bacteria in soil of successional grasslands of the Drentsche A (The Netherlands). FEMS Microbiol Ecol 31:207-215

Legendre P (2008) Studying beta diversity: ecological variation partitioning by multiple regression and canonical analysis. J Plant Ecol $1: 3-8$

Li S, Jiang X, Wang X, Wright AL (2015) Tillage effects on soil nitrification and the dynamic changes in nitrifying microorganisms in a subtropical rice-based ecosystem: a long-term field study. Soil Tillage Res 150:132-138

Muneer M, Oades JM (1989) The role of Ca-organic interactions in soil aggregate stability III mechanisms and models. Aust J Soil Res 27:411423

Nannipieri P, Ascher J, Ceccherini M, Landi L, Pietramellara G, Renella G (2002) Microbial diversity and soil. Eur J Soil Sci 54:655-670

Nicol GW, Leininger S, Schleper C, Prosser JI (2008) The influence of soil $\mathrm{pH}$ on the diversity, abundance and transcriptional activity of ammonia oxidizing archaea and bacteria. Environ Microbiol 10:29662978

Oleszczuk R, Regina K, Szajdak L, Höper H, Maryganova V (2008) Impacts of agricultural utilization of peat soils on the greenhouse gas balance. In: Strack M (ed) Peatlands and Climate Change International Peat Society. Jyväskylä, Finłand, pp. 70-98 
Pastorelli R, Landi S, Trabelsi D, Piccolo R, Mengoni A, Bazzicalupo M, Pagliai M (2011) Effects of soil management on structure and activity of denitrifying bacterial communities. Appl Soil Ecol 49:46-58

Pastorelli R, Vignozzi N, Landi S, Piccolo R, Orsini R, Seddaiu G, Roggero PP, Pagliai M (2013) Consequences on macroporosity and bacterial diversity of adopting a no-tillage farming system in a clayish soil of Central Italy. Soil Biol Biochem 66:78-93

Pellegrino E, Di Bene C, Tozzini C, Bonari E (2011) Impact on soil quality of a 10-year-old short-rotation coppice poplar stand compared with intensive agricultural and uncultivated systems in a Mediterranean area. Agric Ecosyst Environ 140:245-254

Pellegrino E, Bosco S, Ciccolini V, Pistocchi C, Sabbatini T, Silvestri N, Bonari E (2014) Agricultural abandonment in Mediterranean reclaimed peaty soils: long-term effects on soil chemical properties, arbuscular mycorrhizas and $\mathrm{CO}_{2}$ flux. Agric Ecosyst Environ 199:164175

Pereira e Silva MC, Poly F, Guillaumaud N, van Elsas JD, Falcão Salles $\mathrm{J}$ (2012) Fluctuations in ammonia oxidizing communities across agricultural soils are driven by soil structure and $\mathrm{pH}$. Front Microbiol $3: 77$

Pester M, Schleper C, Wagner M (2011) The Thaumarchaeota: an emerging view of their phylogeny and ecophysiology. Curr Opin Microbiol 14:300-306

Philippot L, Bru D, Saby NP, Cuhel J, Arrouays D, Simek M, Hallin S (2009) Spatial patterns of bacterial taxa in nature reflect ecological traits of deep branches of the 16S rRNA bacterial tree. Environ Microbiol 11:3096-3104

Philippot L, Hallin S, Schloter M (2007) Ecology of denitrifying prokaryotes in agricultural soil. Adv Agron 96:249-305

Phillips CJ, Harris D, Dollhopf SL, Gross KL, Prosser JI, Paul EA (2000) Effects of agronomic treatments on structure and function of 
ammonia-oxidizing. Appl Environ Microbiol 66:5410-5418

Picci G, Nannipieri P (2002) Metodi di analisi microbiologica del suolo Franco Angeli, Roma

Priemé A, Braker G, Tiedje JM (2002) Diversity of nitrite reductase (nirK and nirS) gene fragments in forested upland and wetland soils. Appl Environ Microbiol 68:1893-1900

Puglisi E, Zaccone C, Cappa F, Cocconcelli PS, Shotyk W, Trevisan M, Miano TM (2014) Changes in bacterial and archaeal community assemblages along an ombrotrophic peat bog profile. Biol Fertil Soils $50: 815-826$

Purkhold U, Pommerening-Röser A, Juretschko S, Schmid MC, Koops HP, Wagner M (2000) Phylogeny of all recognized species of ammonia oxidizers based on comparative 16S rRNA and amoA sequence analysis: implications for molecular diversity surveys. Appl Environ Microbiol 66:5368-5382

Rotthauwe JH, Witzel KP, Liesack W (1997) The ammonia monooxygenase structural gene amoA as a functional marker: molecular fine-scale analysis of natural ammonia-oxidizing populations. Appl Environ Microbiol 63:4704-4712

Schloss PD, Westcott SL, Ryabin T, et al. (2009) Introducing mothur: open-source, platform-independent, community-supported software for describing and comparing microbial communities. Appl Environ Microbiol 75:7537-7541

Shen JP, Zhang LM, Zhu YG, Zhang JB, He JZ (2008) Abundance and composition of ammonia-oxidizing bacteria and ammonia-oxidizing archaea communities of an alkaline sandy loam. Environ Microbiol 10:1601-1611

Smil V (1997) Global population and the nitrogen cycle. Sci Am $277: 76-81$

Smith J, Wagner-Riddle C, Dunfield K (2010) Season and management 
related changes in the diversity of nitrifying and denitrifying bacteria over winter and spring. Appl Soil Ecol 44:138-146

Soil Survey Staff (1975) Soil taxonomy: a basic system of soil classification for making and interpreting soil surveys USDA-SCS Agric Handb 436 US Gov Print Office, Washington, DC

Stahl DA, de la Torre JR (2012) Physiology and diversity of ammoniaoxidizing archaea. Annu Rev Microbiol 66:83-101

Stephen JR, McCaig AE, Smith Z, Prosser JI, Embley TM (1996) Molecular diversity of soil and marine 16S rRNA gene sequences related to beta-subgroup ammonia-oxidizing bacteria. Appl Environ Microbiol 62:4147-4154

Strack M (2008) Peatlands and Climate Change International Peat Society. Jyväskylä, Finland

AQ13

Stres B, Danevčič T, Pal L, Fuka MM, Resman L, Leskovec S, Hacin J, Stopar D, Mahne I, Mandic-Mulec I (2008) Influence of temperature and soil water content on bacterial, archaeal and denitrifying microbial communities in drained fen grassland soil microcosms. FEMS Microbiol Ecol 66:110-122

Szukics U, Abell GC, Hödl V, Mitter B, Sessitsch A, Hackl E, Zechmeister-Boltenstern S (2010) Nitrifiers and denitrifiers respond rapidly to changed moisture and increasing temperature in a pristine forest soil. FEMS Microbiol Ecol 72:395-406

Tamura K, Peterson D, Peterson N, Stecher G, Nei M, Kumar S (2011) MEGA 5: molecular evolutionary genetics analysis using maximum likelihood, evolutionary distance, and maximum parsimony methods. Mol Biol Evol 28:2731-2739

ter Braak CJF, Šmilauer P (2012) Canoco reference manual and user's guide: software for ordination (version 50) microcomputer power, Ithaca 
Throbäck IN, Enwall K, Jarvis Å, Hallin S (2004) Reassessing PCR primers targeting nirS, nirK and nosZ genes for community surveys of denitrifying bacteria with DGGE. FEMS Microbiol Ecol 49:401-417

Tian XF, Hu HW, Ding Q, Song MH, Xu XL, Zheng Y, Guo LD (2014) Influence of nitrogen fertilization on soil ammonia oxidizer and denitrifier abundance, microbial biomass, and enzyme activities in an alpine meadow. Biol Fertil Soils 50:703-713

Tilman D, Cassman KG, Matson PA, Naylor R, Polasky S (2002) Agricultural sustainability and intensive production practices. Nature 418:671-677

Tourna M, Freitag TE, Prosser JI (2010) Stable isotope probing analysis of interactions between ammonia oxidizers. Appl Environ Microbiol $76: 2468-2477$

Treusch AH, Leininger S, Kletzin A, Schuster SC, Klenk HP, Schleper C (2005) Novel genes for nitrite reductase and Amo-related proteins indicate a role of uncultivated mesophilic crenarchaeota in nitrogen cycling. Environ Microbiol 7:1985-1995

Velthof G, Barot S, Bloem J, Butterbach-Bahl K, de Vries W, Kros J, Lavelle P, Olesen EJ, Oenema O (2011) Nitrogen as a threat to European soil quality. In: Sutton MA, Howard CM, Erisman JW, Billen G, Bleeker A, Grennfelt P, van Grinsven H, Grizzetti B (eds) The European nitrogen assessment. Cambridge University Press, Cambridge, pp. 495-510

Wang X, Han C, Zhang J, Huang Q, Deng H, Deng Y, Zhong W (2015) Long-term fertilization effects on active ammonia oxidizers in an acidic upland soil in China. Soil Biol Biochem 84:28-37

Wang X, Wang C, Bao L, Xie S (2014) Abundance and community structure of ammonia-oxidizing microorganisms in reservoir sediment and adjacent soils. Appl Microbiol Biotechnol 98:1883-1892

Webster G, Embley TM, Prosser JI (2002) Grassland management regimens reduce small-scale heterogeneity and species diversity of $b$ - 
proteobacterial ammonia oxidizer populations. Appl Environ Microbiol $68: 20-30$

Wertz S, Dandie CE, Goyer C, Trevors JT, Patten CL (2009) Diversity of nirK denitrifying genes and transcripts in an agricultural soil. Appl Environ Microbiol 75:7365-7377

Wessén E, Söderström M, Stenberg M, Bru D, Hellman M, Welsh A, Thomsen F, Klemedtson L, Philippot L, Hallin S (2011) Spatial distribution of ammonia-oxidizing bacteria and archaea across a 44hectare farm related to ecosystem functioning. ISME J 5:1213-1225

Wolsing M, Priemé A (2004) Observation of high seasonal variation in community structure of denitrifying bacteria in arable soil receiving artificial fertilizer and cattle manure by determining T-RFLP of nir gene fragments. FEMS Microbiol Ecol 48:261-271

Xie Z, Le Roux X, Wang C, Gu Z, An M, Nan H, Chen B, Li F, Liu Y, Du G, Huyuan Feng H, Ma X (2014) Identifying response groups of soil nitrifiers and denitrifiers to grazing and associated soil environmental drivers in Tibetan alpine meadows. Soil Biol Biochem 77:89-99

Xu YG, Yu WT, Ma Q, Zhou H (2012) Responses of bacterial and archaeal ammonia oxidisers of an acidic luvisols soil to different nitrogen fertilization rates after 9 years. Biol Fertil Soils 48:827-837

Yao H, Campbell CD, Chapman SJ, Freitag TE, Nicol GW, Singh BK (2013) Multifactorial drivers of ammonia oxidizer communities: evidence from a national soil survey. Environ Microbiol 15:2545-2556

Yoshida M, Ishii S, Otsuka S, Senoo K (2009) Temporal shifts in diversity and quantity of nirS and nirK in a rice paddy field soil. Soil Biol Biochem 41:2044-2051

Yu Y, Zhang J, Chen W, Zhong W, Zhu T, Cai Z (2014) Effect of land use on the denitrification, abundance of denitrifiers, and total nitrogen gas production in the subtropical region of China. Biol Fertil Soils 50:105-113 
Zhalnina K, de Quadro PD, Camargo FA, Triplett EW (2012) Drivers of archaeal ammonia-oxidizing communities in soil. Front Microbiol 3:210

Zhang LM, Hu HW, Shen JP, He JZ (2012) Ammonia-oxidizing archaea have more important role than ammonia-oxidizing bacteria in ammonia oxidation of strongly acidic soils. ISME J 6:1032-1045

Zhang LM, Wang M, Prosser JI, Zheng YM, He JZ (2009) Altitude ammonia-oxidizing bacteria and archaea in soils of Mount Everest. FEMS Microbiol Ecol 70:208-217

Zhang X, Liu W, Schloter M, Zhang G, Chen Q, Huang J, Li L, James J, Elser JJ, Han X (2013) Response of the abundance of key soil microbial nitrogen-cycling genes to multi-factorial global changes. PLoS One 8:e76500

Zhao D, Luo J, Wang J, Huang R, Guo K, Li Y, Wu QL (2015) The influence of land use on the abundance and diversity of ammonia oxidizers. Curr Microbiol 70:282-289

Zumft G (1997) Cell biology and molecular basis of denitrification. Microbiol Mol Biol Rev 61:533-616 